\title{
Palavras metafóricas monoicas: tópico e veículo implícitos?
}

\section{RESUMO}

Reginaldo Nascimento Neto nadynhu@ifma.edu.br Araguaína, Brasil.

\begin{abstract}
Este artigo pretende discutir brevemente se o processamento cognitivo da metáfora, por meio de um mecanismo de associação, inferências, comparação e identificação criativa do pensamento a um gabarito mental pode ser responsável pelo uso e menção de palavras metafóricas monoicas, amalgamando tópico e veículo de forma unirreme e implícita, isto é, sem externá-los. Para tanto, parte-se de um vislumbre histórico sobre os conceitos de metáfora concebidos por Aristóteles (1996), Richards (1936), Black (1993), Searle (1993) e Lakoff \& Johnson (2002) para se demonstrar que os elementos essenciais da metáfora, diversamente reconhecidos dependendo do autor como tópico e veículo, Frame e foco, domínio alvo e domínio fonte, S é P e S é R, ou tipo e antítipo, podem ocorrer na esfera do pensamento e produzir palavras metafóricas, percebidas ou não como tal, que se manifestam de forma monoica em vez de na sentença, como advoga o interacionismo. Para tanto, apresentam-se algumas palavras cujas etimologias embutem tópico e veículo. A conclusão a que se chega é que no processo de onomasiologia, como revela o estudo da etimologia, em muitos casos, o uso da metáfora funde em uma só palavra o tópico e o veículo.
\end{abstract}

PALAVRAS-CHAVES: Metáfora. Cognitivismo. Interacionismo. 


\section{INTRODUÇÃO}

O fascínio humano por desbravar as dimensões que se supõem existirem além de cada fronteira já conhecida impulsiona o homem a concebê-las virtualmente pela imaginação. Esses campos agregam-se a seu sistema conceptual e criam novas realidades baseadas em suas experiências de mundo. Conceitos emergentes, conforme Lakoff \& Johnson (2002, p. 210, 245), baseiam-se na constante interação com o mundo físico.

Essa ideia de conceitos emergentes tem se manifestado nas produções artísticas a cada limiar dimensional, como por exemplo, o Mar motivou a publicação dos livros Moby Dick de Herman Melvile em 1851, O Velho e o Mar de Ernest Hemingway em 1951, Mar Sem Fim de Amyr Klimk em 2000, e À Procura de um Navio por John McPhee em 1990; o fundo do mar inspirou Júlio Verne a escrever o livro Vinte Mil Léguas Submarinas - 1869, e a Irwin Allen com o filme Viagem ao Fundo do Mar - 1961, as terras além-mar, Robinson Crusoé de Daniel Defoe em 1719, A Terra Desolada de T.S. Eliot em 1922; o espaço estelar, Star Trek de Gene Roddenberry - filme de 1966, Perdidos No Espaço de Irwin Allen - filme de 1965, Da terra à Lua - Júlio Verne - 1865, Os Primeiros Homens na Lua H.G.Wells - 1901, o tempo, a Máquina do Tempo - H.G. Wells - 1895, O Túnel do Tempo - Irwin Allen - filme 1966; o íntimo humano, O Retrato de Dorian Gray - Oscar Wilde - 1890, O Eu Profundo e os Outros Eus - Fernando Pessoa - s.d., O estranho caso do Dr. Jekyll e o Sr. Hyde - 1886, o Médico e o Monstro, e a sociedade, As viagens de Gulliver - Jonathan Swift -1892, e O capital de Karl Marx em 1867.

Dessa forma, pareceria ingênua a concepção de que haja uma última fronteira a se desbravar. No entanto, o cérebro tem sido considerado como essa última instância que convida ao descortinamento. Obviamente, a palavra última aqui empregada se refere à mais imediata esteira à frente, e não ao sentido de final. De acordo com Marino Jr. (2005, p.30), o cérebro humano foi engendrado com funções elevadas e complexas como os sentidos, o pensamento concreto e abstrato, a memória, a fala, a linguagem, etc.

Foi Alcmeon - séc. $V$ a.C. - quem primeiro concebeu ser o cérebro o órgão da mente, do pensamento e da memória (cf. Marino Jr., 2005, p. 20), no entanto, um século mais tarde, Aristóteles mantinha a visão cardiocêntrica, isto é, que o coração era a sede do intelecto. Esse conceito, embora equivocado, cristalizou-se na etimologia da expressão de cor, ou em inglês, know by heart - saber de coração, ou seja, faz-se inferir que o coração seja a indústria da memória.

No entanto, atualmente, há abundante evidência científica de que é o cérebro o centro de controle do pensamento, da cognição, da linguagem entre outros. Assim, este artigo parte do pressuposto de que o processamento da linguagem, especialmente das metáforas, é uma ação mental. Segundo Pinker (2005, p. 32), a mente é o cérebro que faz, e Lakoff \& Johnson (2002) dizem que as metáforas são o fundamento do pensamento e das ações: 
A metáfora está infiltrada no pensamento e na ação. Nosso sistema conceptual ordinário, em termos do qual não só pensamos, mas também agimos, é fundamentalmente metafórico por natureza. [...] Nossas experiências e atividades são metafóricas por natureza e nosso sistema conceptual é estruturado pela metáfora. (LAKOFF \& JOHNSON, 2002, p. 45 e 245).

Portanto, tomando a declaração de Black (1993, p.30), de que a metáfora é a ponta submersa de um modelo, então, poderiam tópico e veículo estarem imbricados em uma só palavra, resultante da composição prévia mental e não se manifestarem na sentença? Buscar-se-ão doravante respostas a esta problemática, pois segundo Kitay (1987, p. 22-23, apud Fossile, 2015, p. 16), metáforas são sentenças, não palavras isoladas; consistem de dois componentes em tensão, e também entende ser possível identificar nelas tópico e veículo.

Nos estudos da Biologia, há encontrados casos de autofecundação. Isto é, uma fecundação que ocorre entre gametas produzidos pelo mesmo organismo. Certos vegetais e as tênias são monóicos, ou seja, são organismos hermafroditos, possuem em si os dois gametas responsáveis pela reprodução. Por analogia, no que concerne à metáfora, este artigo entende que há palavras que encerram em si mesmas tópico e veículo implícitos. Portanto, metáforas monoicas. Estes dois integrantes da metáfora seriam respectivamente a entidade da qual se fala e que predica algo sobre o tópico. Isto é, o tópico é o elemento do qual se fala e o veículo é o que o predica (FOSSILE, 2015).

\section{ALGUMAS CONTRIBUIÇÕES DAS TEORIAS SOBRE METÁFORA}

A trajetória cronológica seguida pela evolução dos conceitos sobre metáfora tem seu $\alpha \rho \chi \eta$ - arqué ou princípio ab ovo, conforme Coimbra (1999 p.13), em Aristóteles no século IV a. C., e continua suscitando interesse dos estudiosos das áreas da Psicologia, Filosofia e da Linguística.

Urge, a esta altura, compreender a etimologia da palavra metáfora, pois, no mesmo parecer de Virgílio, em Georgica p. 2.490, é feliz aquele que pôde conhecer as causas das coisas - Felix qui potuit rerum cognoscere causas. A palavra metáfora é oriunda do grego $\mu \varepsilon \tau \alpha \phi o \rho \alpha$ e é composta pelos radicais $\mu \varepsilon \tau \alpha$ - meta, que significa para fora ou mais adiante, e $\phi \varepsilon \rho \varepsilon \imath v$ - pherein, que implica em transladar, levar ou conduzir, esse sentido se mantém nas palavras teleférico - (conduzir para longe) e em euforia - (boa condução). Nos ônibus da Grécia moderna ainda se pode ler a inscrição $\mu \varepsilon \tau \alpha \phi o \rho \varepsilon \imath v$ com sentido fossilizado de transportar passageiros de um lugar para outro. Assim, metáfora designa transladar para mais além, ou para outro lugar. Portanto, para Aristóteles (1996) metáfora é a transferência do nome de uma coisa para outra.

Reboul (2004, p. 122) dá eco ao conceito aristotélico ao reverberar que metáfora designa uma coisa com o nome de outra que tenha com ela uma relação de semelhança e acrescenta: semelhança de relações entre termos heterogêneos. Seu exemplo para explicar e validar essa semelhança de relações, Reboul (2004, p. 185) evoca o postulado matemático na equação $a / b=c / x ; \log o x=b c / a$. Se $2 / 3$ $=10 / x, x=15$, assim diz que os quatro termos são diferentes, mas suas relações são idênticas. 
Os conceitos sobre metáfora evoluíram e a cada novo estudo foram agregados novos postulados ampliando a visão sobre o fenômeno da metáfora, até então impossível de ser reproduzido por máquinas e computadores. Abaixo, estão elencadas algumas dessas contribuições que deserdaram a concepção clássica de função meramente ornamental e substitutiva. No entanto, percebe-se que, o conceito de uma coisa com o nome de outra, que tenha com ela uma relação de semelhança, fruto de um sistema associativo da mente permanece.

Quadro expositivo de algumas contribuições das teorias sobre metáfora

\begin{tabular}{|c|c|}
\hline Autor & Postulados \\
\hline $\begin{array}{l}\text { Aristóteles - } \\
\text { Teoria Clássica }\end{array}$ & $\begin{array}{l}\text { A metáfora é a transferência do nome de uma coisa para } \\
\text { outra. Está contida na retórica. (COIMBRA, 1999, p.4). } \\
\text { A ausência do termo comparação na metáfora não implica } \\
\text { que metáfora seja uma comparação abreviada, mas, ao } \\
\text { contrário, que a comparação é uma metáfora desenvolvida. } \\
\text { A comparação diz: "isto é como aquilo", a metáfora diz: } \\
\text { "isto é aquilo". Toda metáfora é uma comparação implícita. } \\
\text { Metáfora é a substituição de um termo por outro. } \\
\text { (RICOEUR, 2000, p.37 e 46). } \\
\text { A metáfora empresta palavras para preencher vãos, } \\
\text { apresenta sentidos impróprios; é ornamental e, não } \\
\text { acrescenta novos conhecimentos. (RICOEUR, 2005, p. 79-81). } \\
\text { Chama de Endoxa o conjunto de opiniões partilhadas pelos } \\
\text { membros de uma mesma comunidade de falantes e que, } \\
\text { posteriormente, é vestida com a roupagem de sistema de } \\
\text { lugares comuns por Black (1962 p. 293). [...] lugares comuns } \\
\text { associados [...] de uma maneira parcialmente dependente } \\
\text { do contexto do uso metafórico, determina um conjunto do } \\
\text { que Aristóteles chamou de endoxa. (BLACK 1993, p. 28). }\end{array}$ \\
\hline $\begin{array}{l}\text { A. Richards (1936) - } \\
\text { Teoria Interacionista }\end{array}$ & $\begin{array}{l}\text { A visão interacionista contrapõe à tradicional substitutiva. } \\
\text { (BLACK, 1993, 27). Traz uma nova visão da retórica como } \\
\text { teoria e pensamento do discurso. (RICOEUR, 2005, p. 123). } \\
\text { Rompeu com o palavracentrismo de Aristóteles. O sentido } \\
\text { da frase não deriva do sentido da palavra mas da frase toda. } \\
\text { (RICOEUR, 2005, p. 126). } \\
\text { A metáfora mantém dois pensamentos heterogêneos } \\
\text { simultaneamente, assim produzindo interação entre eles. A } \\
\text { metáfora nasce no uso. O uso é governado e produzido pelo } \\
\text { pensamento, sendo assim, a metáfora é um instrumento do } \\
\text { pensamento. Enfatizou o caráter binário da metáfora } \\
\text { designando-os de tenor e veículo. Os conceitos, e não as } \\
\text { palavras, é que são a argamassa da metáfora. Falava em } \\
\text { dicotomia entre linguagem e pensamento, dando ênfase ao } \\
\text { pensamento, mas não os conjugando. (MOURA, 2008, p. } \\
\text { 182). }\end{array}$ \\
\hline $\begin{array}{l}\text { Max Black (1962) - } \\
\text { Teoria interacionista } \\
\text { suplementar. (Black, 1993, p. } \\
\text { 19) }\end{array}$ & $\begin{array}{l}\text { A metáfora gera o novo e o criativo e pode produzir leituras } \\
\text { conflitantes e diferentes. (BLACK 1993, p.24). Fala em sistema } \\
\text { de lugares comuns. (BLACK, } 1962 \text { p. 293). Condição Binária da } \\
\text { metáfora sendo assunto primário e assunto secundário. } \\
\text { (BLACK 1993, p.28). A metáfora está baseada em uma } \\
\text { similaridade e analogia. (idem, p. 30). A conexão de } \\
\text { elementos na condição binária para a produção da } \\
\text { metáfora, suprime alguns detalhes e acentua ou acrescenta } \\
\text { outros (RICOEUR, 2000, p. } 129 \text { e 130). Mesmo embora não }\end{array}$ \\
\hline
\end{tabular}




\begin{tabular}{|l|l|}
\hline $\begin{array}{l}\text { John Searle (1993) - } \\
\text { Teoria Pragmática }\end{array}$ & $\begin{array}{l}\text { se declare cognitivista fala em Insight e em operação } \\
\text { intelectual irredutível. }\end{array}$ \\
& $\begin{array}{l}\text { A metáfora foca a distinção entre SS significado da sentença } \\
\text { e SF significado do falante (MOURA, 2009; FOSSILE 2015). A } \\
\text { metaforicidade encontra-se no SF. Evoca a intencionalidade } \\
\text { do falante. Sustenta que as palavras mantêm seu sentido } \\
\text { literal. (SEARLE 1993, p. 84), faz emergir na metáfora os } \\
\text { conceitos de condições de verdade. }\end{array}$ \\
\hline Lakoff \& Johnson - & $\begin{array}{l}\text { A metáfora não é fenômeno exclusivamente linguístico, mas } \\
\text { Teoria Cognitivo. Os processos imanentes do cérebro funcionam } \\
\text { metaforicamente. Esses processos do sistema de } \\
\text { implicações geram inferências e cognição. A metáfora é } \\
\text { conceitual e faz parte imanente do sistema ordinário do } \\
\text { pensamento e da linguagem. Portanto, a metáfora é uma } \\
\text { projeção mental. (LAKOFF \& JOHNSON, 2002, p. 45 e 245) }\end{array}$ \\
\hline
\end{tabular}

\section{O CARÁTER BINÁRIO DA METÁFORA}

Ao se observar em perspectiva as correntes e vieses teóricos acima sobre a metáfora, parece haver uma homologação, ainda que geral, entre elas. Percebese que a condição binária expressa na sentença é sine qua non para a compreensão da metáfora. Para Aristóteles, a ideia de analogia e substituição ancoravam-se em que dados os termos, $A$ está para $B$ tal como $C$ está para $D$, podemos substituir A por C e vice-versa (COIMBRA, 1999, P.4), dessa forma então, A é C. Dessa forma, haveria dois elementos minimamente essenciais na urdidura da metáfora.

Também Richards (1936) enfatizou o caráter binário supostamente explícito da metáfora designando-os de tenor e veículo, enquanto Black, (1993) fala de assunto primário e secundário:

In the context of a particular metaphorical statement, the two subjects "interact" in the following ways: a) the presence of the primary subject incites the hearer to select some of the secondary subjects' properties and b) invites him to construct a parallel implication complex that can fit the primary subject; and, c) reciprocally indices parallel changes in the secondary subject.

No contexto de uma declaração metafórica particular, os dois assuntos "interagem" da seguinte maneira: (a) a presença do assunto primário incita o ouvinte a selecionar alguma das propriedades do assunto secundário; e (b) convida-o a construir uma implicação complexa paralela que possa se ajustar ao assunto primário; e (c) reciprocamente induz mudanças paralelas no assunto secundário. (BLACK, 1993 P.28). (Grifos meus).

Para Searle (1993), de acordo com Finger (1996), também há dois elementos que integram uma metáfora. Trata-se da existência binária de SS - Significado da Sentença e SF - Significado do Falante na composição da metáfora: 
e o significado do proferimento são exatamente o mesmo. (FINGER, 1996, P. 52).

Ainda nessa mesma corrente de proferimentos, Fossile (2015, p. 14) menciona que a interpretação de uma sentença metafórica exige a presença de dois elementos que formam a metáfora: o tópico e o veículo. Estes dois integrantes da metáfora seriam, respectivamente, a entidade da qual se fala e que predica algo sobre o tópico. Isto é, o tópico é o elemento do qual se fala e o veículo é o que o predica.

Ricoeur (2000, p. 129) e Fossile (2015, p. 36-37) dizem que, na metáfora, a unidade semântica deixa de ser apenas palavra para tornar-se a frase toda. Duas coisas diferentes e simultaneamente ativas.

Ricoeur, (2000, p. 130) deixa mais clara essa exigência binária explícita quando diz que: A presença simultânea do conteúdo e do veículo e sua interação é que dão origem à metáfora; desde então o conteúdo não permanece imutável, como se o veículo fosse apenas uma vestimenta ou ornamento.

Black (1993, p. 19) faz uma tentativa de ampliar a formulação original, explicando os fundamentos das metáforas de interação, filtragem e triagem a fim de entender como as declarações metafóricas funcionam e também sugere relações no campo das semelhanças e analogias no intuito de lançar luz sobre as conexões entre metáforas e modelos, no entanto, demonstra apenas mecanismos sintáticos externos frustrando a expectativa criada quando sublima uma veia cognitivista na declaração de que toda metáfora é a ponta submersa de um modelo. (BLACK, 1993, p. 30).

A despeito da diferença de linhas epistemológicas entre os interacionistas Lakoff \& Johnson (2005) e os inatistas Chomsky (2005) e Pinker (2005), Se a metáfora faz parte imanente do sistema ordinário do pensamento e da linguagem, (LAKOFF \& JOHNSON, 2002) e as representações semânticas na mente/cérebro são inatas e universais (CHOMSKY, 2005 p. 316/317), como apoia Pinker, (2005, p.43) ao declarar: a mente possui uma estrutura inata complexa, uma estrutura universal da mente não é só logicamente possível, mas provavelmente verdadeira; então, a mente pensa suas metáforas em mentalês

[...] as sentenças em uma língua falada são juncadas de artigos, preposições, sufixos de gênero e outros condutores gramaticais. Eles são necessários para ajudar a obter informações de uma cabeça para outra via boca e ouvido, um canal lento, mas não são necessários no interior de uma única cabeça, onde as informações podem ser transmitidas diretamente por grossos feixes de neurônios. Assim as declarações em um sistema de conhecimento não são sentenças em inglês, e sim inscrições em uma linguagem de pensamento mais rica, o "mentalês". (PINKER, 2005, p.82).

Ao que Pinker (2005) chama de mentalês, pode-se entender como um sistema de linguagem do pensamento.

\section{SINAPSES DA METÁFORA}


Pensar é competência inata da mente, (Pinker, 2005; Chomsky, 2005) mas, a experiência de vida, o aprendizado, um sistema de lugares comuns, ou a endoxa são elementos importantes e estruturais em como a mente constrói seus filtros de arbítrios para moldar o pensamento.

É evidente que a linguagem é o resultado da inter-relação de dois fatores: o estado inicial e o curso da experiência. Podemos conceber o estado inicial como um sistema de aquisição da linguagem, que toma a experiência como input e fornece a linguagem como output um output que é internamente representado na mente/cérebro ${ }^{1}$. (CHOMKY, 2005, p. 31).

A mente é um platô fotográfico e está constantemente captando imagens e conceitos enquanto os armazena na memória. Pela lei da associação e da metáfora, a mente pode visualizar tudo que está ligado a um símbolo. (WERE, 1979, p. 30-31).

Dada essa capacidade associativa da mente, o elemento pedagógico da metáfora é proativo. Diz Reboul (2004, p. 222) que as metáforas são clássicas em toda linguagem educacional. Deve ser por esse motivo que as metáforas típicas e antítipicas de Jesus de Nazaré tenham resistido aos séculos, permanecendo vívidas na mente de milhões de pessoas até os dias atuais.

Peirce, (2005) acreditava em um sistema de representações associativas ao pensamento, pois diz que tudo aquilo que for totalmente incomparável a alguma outra coisa é totalmente inexplicável porque a explicação consiste em colocar as coisas sob leis gerais ou sob classes naturais, e que:

Finalmente, nenhum pensamento presente concreto tem significado algum, valor intelectual algum, pois estes residem não naquilo que é realmente pensado mas naquilo a que este pensamento pode ser conectado numa representação através de pensamentos subsequentes de forma que o significado de um pensamento é, ao mesmo tempo, algo virtual. (PEIRCE, 2005, p.272).

Como então funcionam as metáforas? Como ela faz associações e habilita a enunciação? Encontram-se aqui duas perguntas para as quais as respostas afiguram-se extremamente complexas e ainda inatingíveis.

Considerando-se que a mente é um sistema primorosamente organizado; e realiza proezas notáveis que nenhum engenheiro é capaz de duplicar (PINKER, 2002, p.33), como perscrutar tamanha complexidade neural?

Sabe-se como visto acima, que a mente é a fábrica das metáforas e da linguagem, e emprega como matéria-prima as experiências vividas, e a aquisição da linguagem. Os estudos do fisiologismo cerebral humano investigam a relação complexa existente entre a tessitura de redes de comunicação neural, processadas pelas sinapses, e as funções mentais superiores.

Para fins de simplificação, a aparência de um neurônio, observado em um microscópio eletrônico, pode ser comparada a um ovo frito visto de cima e que tem, ao longo de todas as suas bordas, ramos incrustrados, de onde irrompem centenas de raízes finas como brotos de feijão. No entanto, de uma das margens, 
alonga-se uma cauda semelhante a uma amarra ou tira de salsichas seguida por mais centenas de estirpes como filamentos desgrenhados.

Por meio da descrição metafórica acima pretende-se fazer visualizar uma célula nervosa composta essencialmente por três regiões responsáveis por funções específicas: o pericário ou corpo, os dendritos - do grego $\delta \varepsilon v \delta \rho o v /$ déndron $=$ árvore - que são curtos, ramificam-se profusamente, e foram desenhados para receber estímulos elétricos que excitam a membrana; e os axônios, - do grego $\alpha \xi_{o v} /$ áxon = eixo - um filamento único porém maior que os dendritos, e servem como transmissores. Neles há um cone de engate, um túbulo condutor e um bastão terminal por onde o axônio entra em contato com os outros neurônios vizinhos para partilhar informações.

O sistema nervoso é composto por um conjunto complexo de neurônios que interagem para partilhar informações conectando-se uns aos outros por meio do processo denominado sinapse e formam uma rede neural. "Por meio de impulsos químicos e elétricos, as ordens cerebrais são transmitidas aos músculos, órgãos e sistemas do corpo para funções autômatas: respiração, batimento cardíaco, etc., e também as de aprendizado e técnicas como andar de bicicleta, jogar tênis de mesa, ler, e assim por diante (NASCIMENTO NETO, 2003, p. 104). Esses impulsos elétricos contendo informação devem percorrer os nervos que chegam aos músculos, mas, ao longo do nervo, encontram resistência. As ramificações de um neurônio não estão sempre em perfeita conexão com as fibras do outro neurônio. (FAYARD, 1975, p. 97).

Assim, quando o cérebro emite um impulso, há resistência no meio do caminho, retardando a velocidade e precisão na performance de obediência corporal, no entanto, à medida que se repete o impulso, as sinapses vão se produzindo mais rapidamente, até que a resistência chega a desaparecer por completo. Os impulsos correm por um canal aberto e os movimentos se executam sem tropeço. (FAYARD, 1975, p. 98).

Decorre daí que, essa intrincada rede de compartilhamento de informações também forma um sistema que é capaz de inferir e produzir cognição, associações e comparações. Diz Pinker, $(2002$, p. 36) que da mesma forma que todos os livros são fisicamente apenas combinações diferentes dos mesmos setenta e tantos caracteres, e que um número finito de notas musicais não signifique que o mundo logo ficará sem melodias, (p. 100), um determinado número de neurônios também engendram inumeráveis conexões.

A ideia de compartilhamento de informações, associação e reconhecimento de elementos precisa de um referencial, pois não se pode esquecer de que tudo aquilo que for totalmente incomparável a alguma outra coisa é totalmente inexplicável (Peirce, 2005).

Decorre daí o postulado de Pinker, (2002, p. 19) concernente ao módulo mental chamado de gabarito, ao asseverar que nosso cérebro mantém um registro da forma e cada rosto e de tudo o que conhecemos, e mesmo com distorções das mais diversas, esse registro ajusta-se à imagem identificando-a. (PINKER, 2002, p. 20).

A partir daí, discorre-se que não seria produtivo o acúmulo de trilhões de dados para designar um gabarito diferente para cada objeto no universo, então prodigaliza-se a organização em categorias mediante semelhanças. Pinker, (2002, 
p. 23 e 229) cita a descoberta de Marr, (1982) concernente à como a visão processa as imagens do mundo externo e o descreve abstrata e internamente em mentalês descartando as informações irrelevantes.

Levando-se em conta que o caráter concreto das imagens mentais permite que elas sejam cooptadas no que se refere a reunir tamanho, forma, localização $e$ orientação em um padrão de contornos, em vez de fatorá-los ordenadamente em asserções separadas, os dados conceituais são arquivados e ficam disponíveis para consulta instantânea, pois a mente forma categorias (PINKER, 2005, p. 310311).

Isso se dá porque, como as imagens são fragmentadas, vislumbres de partes são arranjados em um quadro mental. O processo de captura, compartimentalização, arquivamento, associação e disponibilidade perpassa as seguintes etapas: As pessoas põem as coisas e as outras pessoas em compartimentos mentais e dão nome a cada compartimento. Também formam conceitos que identificam os agrupamentos na textura correlativa do mundo de acordo com seus vários modos de conhecer, ou teorias indutivas que se adaptam aos principais tipos de entidades do mundo e a partir daí, instrumentos de inferência, lógica e probabilidades entram em ação. (idem, p. 325 e 373).

Na perspectiva de que a linguagem do pensamento é combinatória, e conceitos elementares podem ser combinados em ideias cada vez mais complexas (idem, $\mathrm{p}$. 375), e que metáforas podem ser criadas a partir de metáforas, (ibdem, p. 378) então, antes de a metáfora se manifestar por meio de palavras ou sentenças, sua engenharia poderia ocorrer pelo acionamento do dispositivo associativo mental na busca de correspondências significativas de dada informação com o arquivo latente das experiências e moldes gabaritais já estruturados na busca da melhor inferência.

Por exemplo, em: João é um leão, exige-se computar que a informação não fala a respeito de um leão que se chama João. Então, busca-se uma interseção de significados que corresponda a um corolário lógico com o gabarito. Nesse gabarito mental estão contidos moldes característicos pertinentes a um leão e o tópico João deve ser predicado por um ou alguns dos predicativos do veículo leão. A busca por essa associação significativa ocorre nas redes neurais compartilhadas

\section{MANIFESTAÇÃO METAFÓRICA}

Supostamente, como visto acima, a manifestação linguística da metáfora exige a agregação de dois elementos chamados de tópico e veículo, conteúdo primário e secundário, frame e foco, ou SS e SF, etc. Como diz Fossile (2015. p. 12), para ele (Black), a metáfora é o resultado da interação entre as (duas) partes de uma sentença metafórica: (a) tópico: elemento ou entidade da qual se fala, e (b) veículo: entidade que predica algo sobre o tópico. Portanto, situa a metáfora como fenômeno da linguagem.

No entanto, pretende-se doravante demonstrar que, como reza a teoria da metáfora conceptual de Lakoff \& Johnson (1980, 2002), as metáforas funcionam no nível do pensamento e, quando são trazidas à luz pela linguagem sentencial, já haviam sido concebidas. Reafirma-se que, embora interacionista, Black deixava transparecer sua percepção e anuência cognitivista como afirma Finger (1996, p. 
50): Black designa uma forte função cognitiva às metáforas. Elas funcionam como instrumentos cognitivos.

Devido às limitações deste artigo, não se discutirá aqui o que vem a ser literal ou figurativo. Por motivos de clareza, todavia, tomar-se-á o conceito de que literal seja o sentido primário e o figurativo o secundário. Isto é, primário como o elemento do qual se fala e, secundário, que predica o primário.

Ancorado nesse conceito, na sentença: "O homem é o lobo do homem" (REBOUL, 2004, p. 94), tem-se homem, do qual se fala algo, sendo o tópico, portanto literal, e lobo, assumindo o papel metafórico sendo o veículo, que predica o assunto primário. Nesse exemplo, identificam-se claramente tópico e veículo, mas, o que se pode dizer do exemplo abaixo:

Era uma gaiola arredondada! Suas grades pareciam envolver uma espécie de trevo metálico com quatro pétalas encravadas nas bordas de uma esfera que as fazia girar tão rapidamente que davam a impressão de uma nuvem de poeira cinza brincava de ciranda cirandinha ali dentro da jaula. Atrás dessa esfera, havia um mancal preso à parede. Assim como um passarinho olha assustado para um lado e para outro, a gaiola oscilava da direita para a esquerda e, depois da esquerda para a direita, assoprando uma brisa que não podia ficar encarcerada junto ao trevo no interior das grades entrelaçadas. (NASCIMENTO, NETO, 2003).

Observe-se que o texto apresenta a predicação de um ventilador de parede, porém em nenhum momento menciona esse tópico. No entanto, durante a leitura atenta, integraliza-se mentalmente o mosaico dessa imagem. Há veículo, porém não está explicito o tópico. $\mathrm{O}$ mesmo acontece com o seguinte texto:

Existem no topo desse grande cubo metálico branco, quatro tochas e uma enorme grade negra que as circundava formando quarteirões. Sua barriga é uma sauna de $400^{\circ}$ graus. Dentro dela, o estrepitar de ossos já esturricados sonoriza algo similar a uma valsa lenta. Um galináceo despido dança suavemente ao centro sob a luz oriunda do fundo desse túnel. O calor faz exalar um aroma de gordura derretida, mas, é do lado de fora que um filhote de elefante estende sua tromba amarela como que tocando o lado do prédio. Mesmo respirando fundo, reprime flatos em fluxo contínuo para manter a chama das tochas e o funcionamento da sauna. Há um chapéu retangular de vidro pronto para cobrir a grade superior e as tochas. Sobre uma dessas chaminés, há um caldeirão tocando apito de fábrica, esse apito gira sobre um pino perfurado ao meio como vulcão.

Novamente, esta descrição metaforiza um fogão, porém, apenas exibe o veículo, sendo o tópico cristalizado no pensamento. Tópico e veículo não estão expressos no texto. Mesmo assim ocorre uma metáfora, que bem pode ser chamada de metáfora monoica.

No que concerne à metáfora, haveria também palavras que encerram em si mesmas tópico e veículo implícitos? Portanto palavras metafóricas monoicas? Observem-se as palavras abaixo. Elas apresentam o princípio de uma coisa com o nome de outra que tenha com ela uma relação de semelhança, porém, sua etimologia encapsula os elementos associativos do tipo: como, assim como, 
semelhante a, similar, tal qual, comparável à, equivalente, homogêneo, correlato a, igual, idêntico, análogo, símile de, que lembra a, ou parecido com, etc., que podem ser facilmente entrepostos entre tópico e veículo mentais, e é o que deve ter acontecido durante o processo onomasiológico.

Os dicionários etimológicos de Pepper (1949), Skinner (1963) e Simões (2014) apresentam os elementos associativos envolvidos na formação onomástica de algumas palavras empregadas na medicina. A seguir, algumas delas são apresentadas como veículos pospostos a seus tópicos inferidos da etimologia. Entremeiam-se os elementos comparativos para ressaltar sua associação mental.

\section{Alantoide}

O dicionário Figueiredo (1913), diz que alantoide é uma Membrana do feto dos mamíferos, durante os dois primeiros meses de vida intrauterina, e da qual se formam a bexiga e a placenta. A estrutura ligada à parte posterior do intestino do embrião. Deriva do grego allas, ou salsicha - allantoeidés, és, és, ou seja em forma de salsicha. Esse órgão dos embriões dos vertebrados superiores, tem forma de forma de cilindro botuliforme ou saco e se desenvolve como um divertículo do canal digestivo funcionando como órgão digestivo e respiratório.

Portanto, a estrutura ligada à parte posterior do intestino (tópico) assemelha-se à salsicha. (veículo). Pode-se dizer que esse órgão é como, semelhante à, similar à, comparável à, equivalente à uma salsicha. Ocorre aí uma metáfora entre a estrutura do intestino ( tópico) denominada de alantoide e a uma salsicha ( veículo).

O mesmo processo acontece com as palavras abaixo:

\section{Ameboide:}

Segundo a etimologia de Cunha (2010), a palavra ameba é oriunda do latim amoeba que por sua vez procede do grego ameibein e significa de forma inconstante, mudar, transformar-se. Essa palavra passou por amoibaios $\alpha \mu о \imath \beta \alpha \imath \sigma \sigma$, que significa em troca ou aquele que muda, que fica se alternando (PEREIRA, 1998). A composição do grego Amoib (é)), ameba e Eid, tem aspecto de, parecido com, resulta em o que se parece com uma ameba, ou que fica mudando de forma. Portanto, ocorre metáfora quando algo (tópico) se semelha à, é similar à, é comparável à, é equivalente à, ou tem forma de uma ameba.

\section{Espermatozoide:}

Da palavra grega Sperma $\sigma \pi \varepsilon \rho \mu \alpha$, que significa semente, e composta de Sper $\Sigma \pi \varepsilon \rho$ para designar $\mathrm{o}$ ato de inseminar mais o sufixo ma - matós $\mu \alpha-\mu \alpha \tau o \sigma$ traduzido por meio ou instrumento e zôon $\zeta \omega o v$ para animal mais eidos $\varepsilon l \delta o \sigma-$ aparência de. Tal composição deu-se porque se acreditou que no interior dessa célula se via, em miniatura, a forma quase completa do animal a que ele pertencia. Portanto, o animal que tem forma de semente.

Nessa palavra ocorre uma metáfora monoica ao embutir o tópico gameta e o veículo semente para designar o instrumento de fecundação que se assemelha à semente prototípica do ser. Perceptível na sentença: Essa célula (tópico) é uma semente (veículo).

4. Lentes: 
Lente é um disco de vidro côncavo de um lado e convexo do outro, ou de qualquer outra substância, que refrange os raios luminosos utilizado nos instrumentos de ótica, que se usa para corrigir os vícios de refração da vista. Ela assemelha-se a uma lentilha ( Lens esculenta), uma leguminosa de folíolos ovais pequenos, flores alvacentas ou violáceas e vagens curtas.

Portanto, existe metáfora na palavra lente, pois, uma coisa ( lente - disco de vidro côncavo de um lado e convexo do outro ) - Tópico - com o nome de outra ( lentilha - leguminosa de folíolos ovais ) - veículo - que tenha com ela uma relação de semelhança ( forma ovoide e convexa).

\section{Câncer:}

Segundo o Instituto nacional do Câncer - INCA - Câncer é o nome dado a um conjunto de mais de 100 doenças que tem em comum o crescimento desordenado de células que invadem os tecidos e órgãos, podendo espalhar-se para outras regiões do corpo. Essas células tendem a ser muito agressivas e incontroláveis, determinando a formação de tumores ou neoplasias malignas.

A palavra câncer vem do grego karkínos, e do latim Cancrum que significa caranguejo, e foi utilizada pela primeira vez por Hipócrates, o pai da medicina, que viveu entre 460 e 377 a.C. (PEPPER, 1949).

As veias que rodeiam um tumor se pareciam com as patas de um caranguejo, isto é, um crustáceo decápode, braquiúro, encontrado em diversos ambientes, tanto de água doce e salgada como terrestres; de carapaça larga, suas pernas têm forma de fortes quelópodes ou apêndices ramificados do abdome flexionados por baixo do corpo.

Dessa forma, a palavra câncer é uma metáfora monoica, pois, uma coisa (câncer tumor) - Tópico - com o nome de outra (caranguejo - crustáceo ) - veículo - que tenha com ela uma relação de semelhança ( ramificações).

\section{Piloro:}

Em conformidade com Aurélio (2001), piloro é uma pequena abertura que faz a comunicação entre o estômago e o duodeno. Trata-se de uma constrição musculosa na região terminal do estômago que regula a passagem do suco alimentar para o duodeno.

Pylorus, do Grego é o termo atribuído ao guarda do portão, derivado de Pyle. Dessa forma, a palavra Portão passa a ser tópico para o canal de saída do estômago - o veículo, na formação de uma metáfora.

\section{Pacenta:}

Placenta: é um órgão materno-fetal desenvolvido na gravidez, que torna possíveis as trocas entre as circulações sanguíneas materna e fetal e que segrega hormônios indispensáveis à manutenção e evolução da gestação.

A Origem desse termo se provém do grego Plakuos, nome culinário que se dava na Grécia, a um bolo achatado e arredondado. A raiz Plak, tem origem indoeuropeia e indica uma forma achatada. Portanto, placenta lembra a um bolo.

Depreende-se daí que, a palavra placenta é uma metáfora monoica, pois, uma coisa (órgão materno-fetal) - Tópico - com o nome de outra (bolo - massa à base de farinha de trigo, assada em forma, geralmente com ovos, açúcar e outros 
ingredientes) - veículo - que tenha com ela uma relação de semelhança (massa achatada).

8. Seios:

Seios são cada uma das duas projeções hemisféricas situadas sobre a camada subcutânea por cima do músculo peitoral feminino. No processo onomasiológico para a nominação desse órgão, aplicou-se a palavra latina Sinus que era empregada com o sentido de bolso, vela náutica, arco ou espaço oco.

Procedente da analogia entre o pano que se prende ao mastro da embarcação para movê-la pela força do vento quando inflada e a forma que têm as glândulas mamárias humanas, é possível perceber a ocorrência de uma metáfora monoica ao se declarar que, a palavra seio enquadra-se no princípio de uma coisa (órgão feminino) - Tópico - tendo o nome de outra (vela náutica) - veículo - que tenha com ela uma relação de semelhança (aparência de oco).

9. Pênis:

Segundo o dicionário de termos médicos, ao órgão genital masculino dos vertebrados superiores que, nos mamíferos, é constituído por dois corpos cavernosos e um tubo central, por onde passa a uretra, tendo na sua extremidade a glande peniana, onde termina o meato urinário, dá-se o nome de pênis. Ela deriva do latim Cauda. O órgão masculino, quando pendente, teria semelhança com uma cauda.

Entende-se que a palavra pênis é uma metáfora monoica, tendo-se em vista que uma coisa (órgão genital masculino) - Tópico - tem o nome de outra (cauda) veículo - que tenha com ela uma relação de semelhança (protuberância).

Entre os romanos, uma palavra popular para pênis era gladius espada, por associação, contribuiu para o nome vagina. Vagina do latim Vagina, e significa bainha ou vagem. Portanto, a genitália feminina era tópico para o veículo bainha.

\section{CONSIDERAÇÕES FINAIS}

Diante do proscênio de elementos aqui apresentados, é possível inferir que o cérebro, sendo o centro de controle do pensamento, da cognição, da linguagem entre outros, articula a produção de metáforas. 0 cérebro tem sua base de processamento da cognição mediante um trabalho de associações que se viabilizam por meio de sinapses na rede neural.

Sendo o sistema conceptual do pensamento fundamentalmente metafórico, então, o cérebro pensa metaforicamente, porém, sua linguagem é muito mais rápida e associada que a linguagem verbal. Tal comportamento comunicativo interno do cérebro é chamado de mentalês.

A trajetória cronológica das contribuições dos teóricos da metáfora tem demonstrado que o conceito primário de que uma metáfora seja uma coisa com o nome de outra que tenha com ela uma relação de semelhança tem se mantido inalterado. No entanto, novas investigações e estudos trouxeram crescimento quanto às funções da metáfora e sua produção, não cabendo mais apenas a ideia aristotélica de modo de ornamento da linguagem. 
Em geral, embora os autores pareçam homologar a ideia de que a condição binária da metáfora expressa na sentença seja sine qua non para sua compreensão, muitos deles deixam exalar um viés cognitivo, onde a ocorrência da metáfora seja no pensamento.

Dessa forma, é possível que tópico e veículo preexistam nos processos mentais e não precisem ser expressos paralelamente para que ocorram metáforas linguísticas. Portanto, seria perfeitamente possível, haver palavras metafóricas monoicas, isto é, palavras que incorporem imanentemente o tópico e o veículo.

O processamento cognitivo da metáfora, por meio de um mecanismo de associação, inferências, comparação e identificação criativa do pensamento a um gabarito mental pode ser responsável pelo uso e menção de palavras metafóricas monoicas, amalgamando tópico e veículo de forma unirreme e implícita, isto é, sem externá-los.

As partes integrantes da metáfora reconhecidos dependendo do autor como tópico e veículo, frame e foco, domínio alvo e domínio fonte, $S$ é P e S é $R$, ou tipo $e$ antítipo, podem ocorrer na esfera do pensamento e produzir palavras metafóricas monoicas, pois há palavras que encerram em si mesmas, tópico e veículo implícitos, fato que diverge do conceito de Kitay (1987, p. 22-23, apud Fossile, 2015, p. 16) de que metáforas são sentenças, não palavras isoladas

Os indícios que se manifestam levam a crer que, em muitos casos, o uso da metáfora funde em uma só palavra o tópico e o veículo. É possível ver que a etimologia de alguns termos encapsula o princípio de uma coisa com o nome de outra que tenha com ela uma relação de semelhança, quando se inserem elementos associativos do tipo: como, assim como, semelhante $a$, similar, tal qual, comparável à, equivalente, homogêneo, correlato a, igual, idêntico, análogo, símile de, que lembra a, ou parecido com, etc., que podem ser facilmente entrepostos entre tópico e veículo mentais, e é o que pode ter acontecido durante o processo onomasiológico. 


\title{
Monoic metaphoric words: implicit topic and vehicle?
}

\begin{abstract}
This shifting intends briefly to discuss if the metaphor cognitive process, by means of a mechanism of association, inference, comparison and creative identification to a mental template, could be responsible for use and mention of monoecious metaphors amalgamating topic and vehicle in an unirreme and implicit way, it means, without externalize them. For that, it starts with a historic glimpse on the metaphor conceived by Aristoteles (1996), Richards(1936), Black (1993), Searle (1993) and Lakoff \& Johnson(2002) to evidence that the metaphor essential elements, diversely recognized, depending on the author as topic and vehicle, frame and focus, target domain, source domain, $\mathrm{S}$ is $\mathrm{P}$ and $\mathrm{S}$ is $\mathrm{R}$, or type and antitype, may occur in the though sphere and beget metaphoric words, perceived or not as a metaphor, manifested in a monoecious form instead in the sentence as interactionism advocates. For that, some words which etymology envelop topic and vehicle. The conclusion obtained portrays that during the onomasiological process, as reveled by the etymology study, in many cases, the metaphor fuses topic and vehicle in just one word.
\end{abstract}

KEYWORDS: Metaphor. Cognitivism. Interacionism. 


\section{NOTA}

${ }^{1}$ Mente/cérebro aqui assume o conceito de (Pinker, 2002, p. 75) de que a mente é o cérebro em atividade.

\section{REFERÊNCIAS}

ARISTÓTELES. Poética. Tradução: SOUZA, E. de. Porto Alegre: Globo, 1996.

BLACK, M. Metaphor. In: Models and metaphor. Ithaca: Cornell University Press, cap. 3, 1962.

Como as metáforas funcionam: uma resposta a D. Davidson. In: SACKS, Sheldon (Org.). Da metáfora. São Paulo: Educ, 1992.

More about metaphor.

In: ORTONY, A. (Ed.). Metaphor and thought. Cambridge: Cambridge University Press, 1993.

Modelos y metáforas. Madrid: Tecnos, 1966. p. 205-238. BOAS, G. A. de V. Metáforas conceptuais de tempo, vida e morte na construção colaborativa das leituras de um texto literário. 2010.

COIMBRA, R. L. A linguagem metafórica. 1999. Tese (Doutorado em Letras/Linguística) - Curso de Pós-Graduação em Letras/Linguística, Universidade de Aveiro, Aveiro, 1999.

CHOMSKY. Noam. Novos horizontes no estudo da linguagem e da mente. Tradução de março Antônio Sant'ana. Editora Unesp. São Paulo. 2005.

CUNHA, Antonio Geraldo da. Dicionário Etimológico da Língua Portuguesa. 4a . ed. Rio de Janeiro: Lexicon, 2010.

FAYARD. Marcelo, I. A Chave da Felicidade e a Saúde Mental. 7ạ. ed. São Paulo: CPB, 1975.

FIGUEIREDO, Candido de. Novo Dicionário da Língua Portuguesa. Lisboa. 1913.

FINGER, I. Metáfora e significação. Porto Alegre: EDIPUCRS, 1996. 
FOSSILE, D. K. Interpretação de metáforas com verbos de mudança de estado. Revista Ciências e Cognição. Rio de Janeiro, v. 13, n. 3, p. 187-198, 2008a.

Metáforas verbais. Um estudo analítico descritivo. Eduft Palmas

2015.

Semântica \& Pragmática: campos in/dependentes. Revista Polidisciplidinar Eletrônica da Faculdade de Guaicará, Guarapuava, v. 1, n. 2, p. 40-58, 2009.

LAKOFF. George. E Johnson. Mark. Metáforas da vida cotidiana. Tradução de Mara.

MARCUSCHI, L.A. Cognição e linguagem: praticas interacionais. Rio de Janeiro: Lucerna, 2007.

MARINO, Jr. Raul. A religião do cérebro: as novas descobertas da neurociência a respeito da fé humana. São Paulo: Editora Gente, 2005

MOURA, H. M. M. Metáfora: das palavras aos conceitos. Letras de Hoje, Porto Alegre, v. 40, n. 139, p. 51-69, 2005.

interpretação de metáforas. Revista Veredas, 6-1, 2002, p. 153-161.

The conceptual and the linguistic factors

in

the use of metaphors. DELTA. São Paulo, v. 22, n. especial, p. 81-94 2006.

NASCIMENTO, NETO. Reginaldo. The Interactive Synapse in English. São Luís: Edugraf, 2003.

PEIRCE. Charles Sanders. Semiótica. 3. ed. São Paulo. Perspectiva, 2005.

PEPPER, OHP. Medical etymology. Editora Saunders, Philadelphia, 
PEREIRA, Isidoro, S.J. Dicionário Grego-Português. 8ạ. ed. Livraria A. I. Braga. S.d.

PINKER. Steven. Como a mente funciona. 2. 4.ed. Reimpressão. Tradução de Laura TEIXEIRA, Mota. São Paulo: Cia das Letras. 2005.

REBOUL. Oliver. Introdução à retorica. Tradução de ícone Castilho Benedetti. São Paulo:

RICOUER, P. A metáfora viva. São Paulo: Loyola, 2005.

RICHARDS, I. A. The philosophy of rhetoric. Oxford: Oxford University Press, 1936.

ROUSSEAU, J. J. Ensaio sobre a origem das línguas. São Paulo: Nova Cultural, 1987. (Coleção Os pensadores).

SEARLE, J. Metaphor. In: ORTONY, A. (Ed.). Metaphor and Thought. 2. ed. Cambridge: Cambridge University, 1993. p. 83-111.

SARDINHA. Tony Berber. Metáfora. São Paulo: Parábola. 2007.

SKINNER HA. The origin of medical terms. Baltimore. Williams \& Wilkins, 1963.

Were. Louis $f$. The certainty of the third angel's message. Editora First impressions MI USA 1979.

ZANOTTO, Sophia. Campinas. São Paulo: Mercado das letras. 2002.

"O que é câncer?", in INCA. Instituto Nacional do Câncer, http://www.inca.gov.br/conteudo_view.asp?id=322 [consultado em 20-092017].

"bolo", in Dicionário Priberam da Língua Portuguesa [em linha], 20082013, https://www.priberam.pt/dlpo/bolo [consultado em 20-09-2017]. 
"Pénis", in Dicionário infopédia de Termos Médicos [em linha]. Porto: Porto Editora, 2003-2017. [consult. 2017-09-20 14:43:50]. Disponível em: 〈https://www.infopedia.pt/dicionarios/termos-medicos/pénis $>$.

Recebido: 30 out. 2016

Aprovado: 12 set. 2017

DOI: $10.3895 /$ rl.v19n25.4929

Como citar: NASCIMENTO NETO, Reginaldo. Palavras metafóricas monóicas: tópicos e veículos implícitos?

R. Letras, Curitiba, v. 19, n. 25, p. 51-69, jan./jun. 2017. Disponível em: <https://periodicos.utfpr.edu.br/rl>.

Acesso em: XXX.

Direito autoral: Este artigo está licenciado sob os termos da Licença Creative Commons-Atribuição 4.0 Internacional. 